\title{
Sleep Disorder Therapy
}

National Cancer Institute

\section{Source}

National Cancer Institute. Sleep Disorder Therapy. NCI Thesaurus. Code C15541.

Any treatment that is undertaken with the purpose of alleviating any form of sleep disorder. 